\title{
Effect of Seismic Joint in the Performance of Multi-Storeyed L-Shaped Building
}

\author{
M.G.Shaikh ${ }^{1}$, Hashmi S.Shakeeb ${ }^{2}$ \\ ${ }^{1}$ (Associate Professor, Department of Applied Mechanics, Govt. College of Engineering Aurangabad, India) \\ ${ }^{2}$ (Department of Applied Mechanics, Govt. College of Engineering Aurangabad, India)
}

\begin{abstract}
The choices of building shapes and structural systems have significant effect on their seismic performance. While symmetrical buildings result in a fairly uniform distribution of seismic forces throughout its components. Unsymmetrical buildings result in highly indeterminate distribution of forces making the analysis and prediction more complicated. L-shaped buildings are among those unsymmetrical structures which are most commonly found in practice in the form of school, office, commercial buildings. In this work three dimensional models of L-shaped buildings are investigated for their seismic performance, varying bay length and storey height. These models were analysed for three conditions viz with gap, with seismic joint and with neither of these. The modeling of structures analysis is carried out using STAAD Pro V8i, also the performance is analysed providing brick infill and compared with, without infill condition. Performances is measured in terms of displacements, axial forces, bending moments, shear forces and compared for those conditions mentioned in the identified column viz., corner, intermediate and interior.
\end{abstract}

Keywords : Brick infill, seismic joint, separation gap, without brick infill.

\subsection{General}

\section{INTRODUCTION}

India is considered as one of the most disaster prone countries in the world. It has experienced [1] several earthquakes in the past resulting in a large number of deaths and severe property damage. The experiences from the past strong earthquakes prove that the initial conceptual design of a building is extremely important for the behaviour of the building during an earthquake. From the past earthquake [2] it is observed that many common buildings and typical methods of construction lack in basic resistance to earthquake forces. In most cases these can be achieved by simple and inexpensive principles of good construction practice. But we know that structure cannot withstand the large earthquakes, but one can develop the structure, which can efficiently look after the design earthquakes.

There are different irregularities [3] in the structure such as plan irregularity, vertical irregularity, torsional irregularity, and mass irregularity. These irregularities prove damaging to the structure in earthquake. To avoid or minimize the ill effects of these irregularities, seismic joints may be provided at appropriate places. In the recent times earthquake engineering concentrated on the development of technology to protect human lives from earthquake disasters. Performance-based [4] design aims to construct a building that satisfies the planned performance of a structure under a given set of loading conditions. Extensively research is needed to achieve this design methodology.

Dubey and Sangamnerkar [3] analyzed different irregularity and torsional response due to plan and vertical irregularity to analyze "T"-shaped building, while earthquake forces acts and to calculate additional shear due to torsion in the columns, and concluded that additional shear due to torsional moments needs to be considered because, this increase in shear forces causes columns to collapse. So in design procedures this additional shear must be taken into account. William [5] converted the perimeter gravity frames to moment resisting frames as a retrofit measure, adding diagonal bracing to the perimeter frames, tying the two structures of L-shaped structure together at each floor level, and using viscous dampers as attachments between the buildings. Osamu and Shirley [6] evaluated the potential of the control system to effectively reduce the building responses in L-shaped, 8-story building with additional vertical irregularity. Ferhi and Truman [7] studied inelastic behavior of an asymmetric single storey building under monotonic loads. In these studies, asymmetric building systems were classified into three groups according to the ratio between the stiffness eccentricity and strength eccentricity, and the behavior of each group was summarized. They concluded that the elastic deformations are dependent primarily on the stiffness eccentricity (not strength eccentricity), while the inelastic deformations are strongly dependent on both stiffness and strength eccentricities. Kan and Chopra [8] have studied the elastic earthquake responses of a torsionally-coupled single story building using response spectrum analysis. It was concluded that the maximum base shear in a torsionally-coupled system is smaller than in the corresponding uncoupled (symmetric) system, while the torque generally increases with the eccentricity between the center of resistance and the center of mass. Lopez, Oscar and Elizabeth [9] aims to identify and 
analyze the advantages and disadvantages associated with building plan shape considering engineering and architectural needs and to quantify them in terms of the common language of costs and benefits. From the available literature, it is understood that due to the advancements in technologies and resources, irregular structure and complex structures are striking and dominating, setting a challenge for structural engineers. Available literature is ample to get a basic idea about the functionality and discrepancies involved in irregular configurations but however extensive studies are required to counter the effects.

\subsection{Necessity}

New globally oriented design methods and construction techniques have been revised in recent years to improve the seismic safety of buildings. In particular, it is now well acknowledged that seismic design must consider the system ability to dissipate energy and the effects of the lateral deformation on the response of the entire building. The ad hoc demand stresses the need to focus on complex building shapes like L, T, C, + and so on rationalizing the perspective of current trend towards aesthetics and site aspects discarding its after effects. The main complexities involved in such complex shapes are dynamic behavior due to stress concentration in reentrant corners and torsion. They are most weak zones liable to tension failure due to heavy concentration of stresses. L-Shaped buildings though are not preferable as per standard codes; the emerging aesthetic views demand such irregular shapes. So, proper studies should be made to make such irregular shapes safe and serviceable. The development of these new architectural forms of buildings and the discrepancies involved in such complex structures due to earthquakes, proposes a better research on the seismic performance of L-shaped buildings.

\subsection{Common Practice}

The plan of buildings like an L, T, H,C and + etc. or a combination of these shapes are most useful and traditional set of building shapes, which enable large plan areas to be accommodated in relatively compact form, yet still provide a high percentage of perimeter rooms with access to air and light. These configurations are so common and familiar that the fact that they represent one of the most difficult problem areas in seismic design may seem surprising. Examples of damage to re-entrant corner type buildings are common, and this problem was one of the first to be identified by observers. There are two basic alternative approaches to the problem of the re-entrant corner forms: structurally to separate the building into simpler shapes or to tie the building together more strongly. Structurally separated entities of a building must be fully capable of resisting vertical and lateral forces on their own, and their individual configurations must be balanced horizontally and vertically. To design a separation joint, the maximum drift of the two units must be calculated by the structural consultant. The worst case is when the two individual structures would lean toward each other simultaneously, and hence the sum of the dimension of the separation space must allow for the sum of the building drifts. Several considerations arise if it is decided to dispense with the separation joint and tie the building together. Collectors at the intersection can transfer forces across the intersection area, but only if the design allows for these beamlike members to extend straight across without interruption. Even better than collectors, are full-height continuous walls in this same location. Since the portion of the wing which typically distorts the most is the free end, it is desirable to place stiffening elements at that location to reduce its response. The use of splayed rather than right angle re-entrant corners lessens then stress concentration at the notch. This is analogous to the way a rounded hole in a steel plate creates less stress concentration than a rectangular hole, or the way a tapered beam is structurally more desirable than an abruptly notched one.

\subsection{Codal provisions}

In India, Codal provision on pounding phenomenon [10] was included in the current revision of IS: 1893-2002. It recommends that the separation between two adjacent units or buildings shall be separated by a distance equal to the amount response reduction factor (R) times the sum of the calculated storey displacements to avoid damage of the two structures when the two units deflect towards each other. When the two buildings are at the same elevation levels, the factor R may be replaced by $\mathrm{R} / 2$. This clause assumes only two dimensional behaviors of building i.e., only translational pounding, but no torsional pounding. But in reality torsional pounding tends to be more realistic than uni-directional pounding during real ground motions. The basic drawback in our codal provisions is that it uses linear methods only.

\subsection{Statement of the problem}

In this work we considered L-shaped building model formed by joining or connecting a rectangular building unit with a square building unit. It proves a complete asymmetrical case. The study focuses on the effect by providing the Elastomer as seismic joint between the adjacent units of L-shaped building. Elastomer is a shock absorbing material proved for its efficient utilisation in mechanical engineering as vibration insulator. Also conventional for its high elasticity, resistance to environmental influences, good dynamic performance, 
low compressibility, almost linear relationship between stress and strain at strains up to 15-20\%. Analysis using STAADPRO Vi8 is carried out to analyse the L-shaped building considering and comparing the effects of relative height, bay length, brick infill, separation gap and seismic joint. The results as required for the study are obtained as axial forces, shear forces, displacements and bending moments.

\section{Numerical Modeling of L-Shaped Building}

L-shaped reinforced concrete building models of five, fifteen, twenty-five and thirty-five storeys each with three different bay lengths $(4 \mathrm{~m}, 6 \mathrm{~m}$, and $8 \mathrm{~m})$ are modeled using STAADPRO Vi8. The structures are assumed to be located in seismic Zone - $\mathrm{V}$ on a site with medium soil. Response reduction factor as 5 for special moment resisting frame [11] is considered for seismic analysis. Building contains different irregularities like Plan irregularity and Re-entrant corner irregularity which induces torsion. Analysis is performed using STAADPRO Vi8 to analyze models with brick infill and without infill including separation gap, without separation gap and with seismic joint conditions in each case. The analysis was performed for nine columns as shown in fig. 2.2.

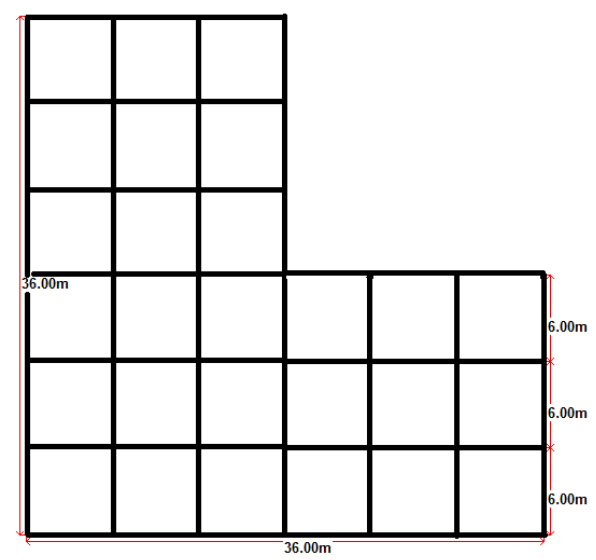

Figure 2.1: Plan of L- Shaped Building

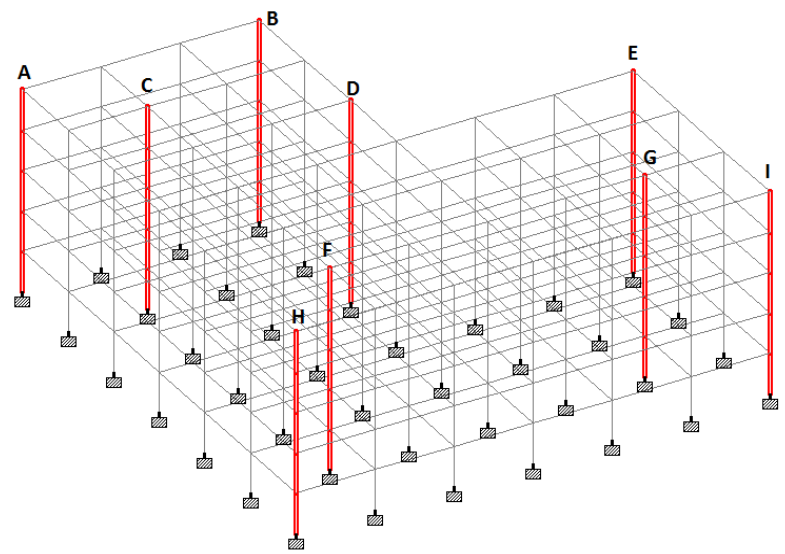

Figure 2.2 Schematic Representations of Column Positions

\subsection{Graphs}

\section{Results And Discussions}

As the study is extensive, we organized the work into graphs as shown below considering the cases which proved effective. Also the effectiveness is disclosed as observed percentage reduction.

\subsubsection{Graphs without In-filled Wall}

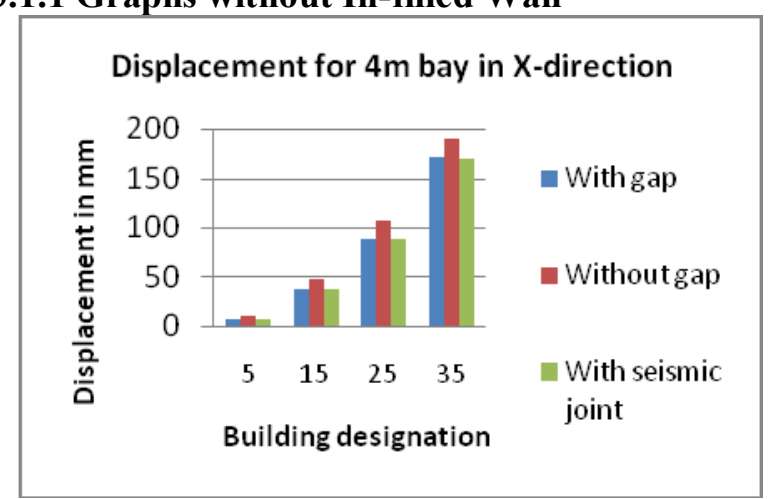

Fig.3.1. Displacement for $4 \mathrm{~m}$ bay in $\mathrm{X}$-direction

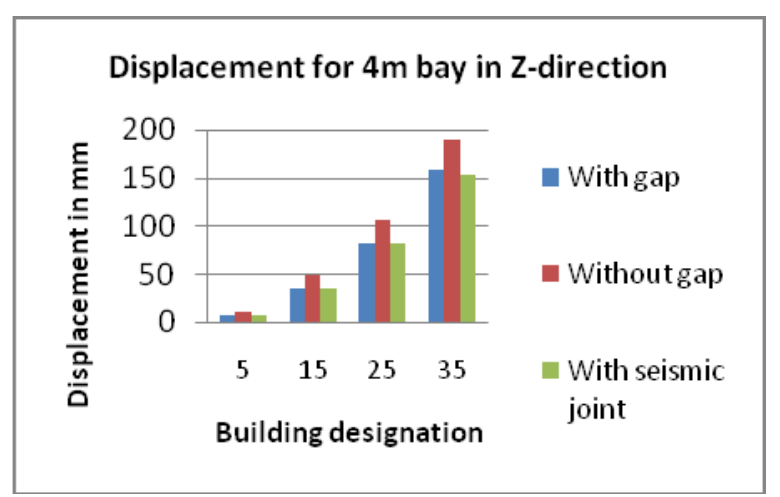

Fig.3.2. Displacement for $4 \mathrm{~m}$ bay in $\mathrm{Z}$ - direction 


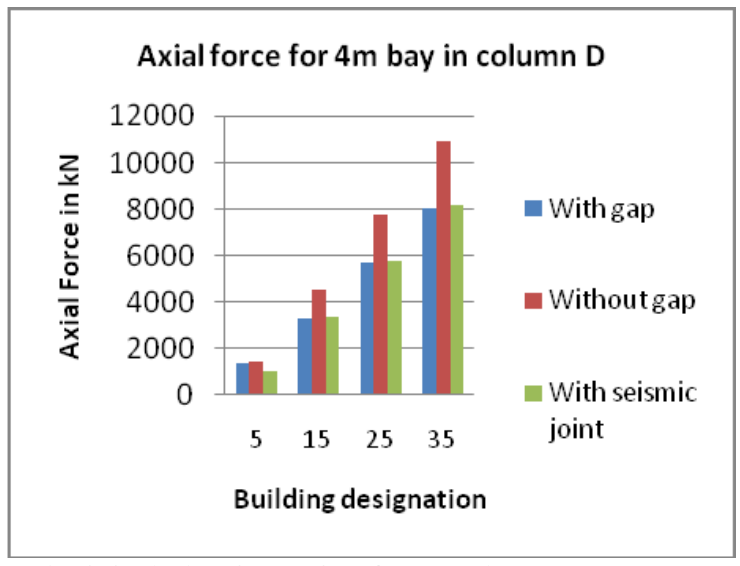

Fig.3.3. Axial force for $4 \mathrm{~m}$ bay in column-D

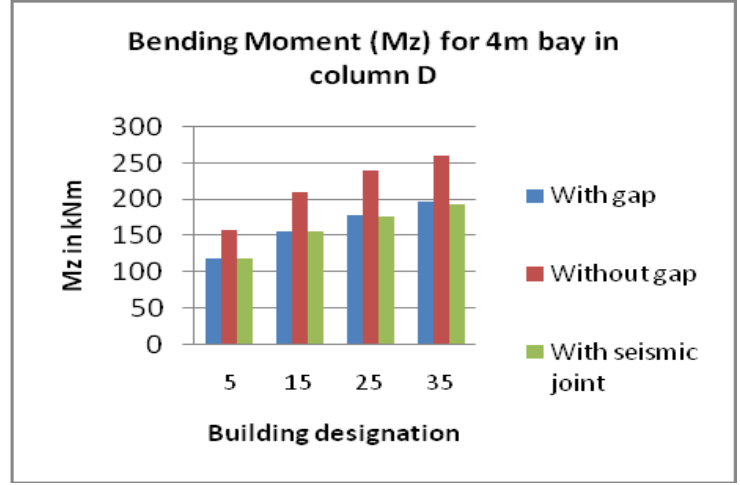

Fig.3.5.Bending Moment for $4 \mathrm{~m}$ bay in column-D

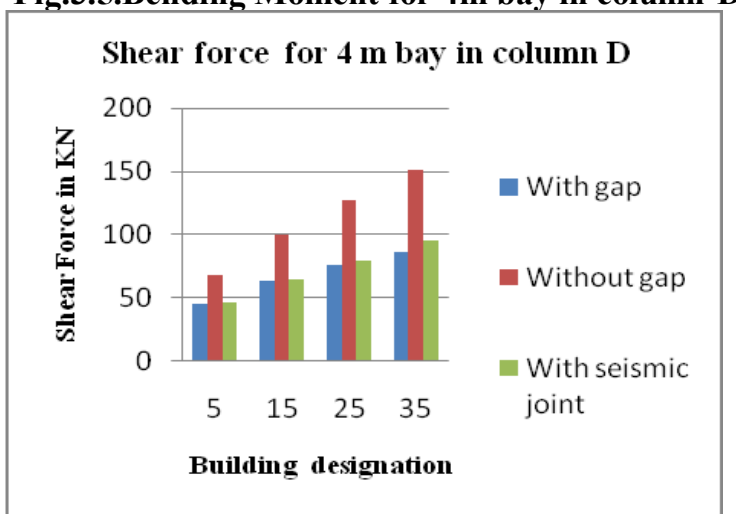

Fig.3.7. Shear force for $4 \mathrm{~m}$ bay in column-D

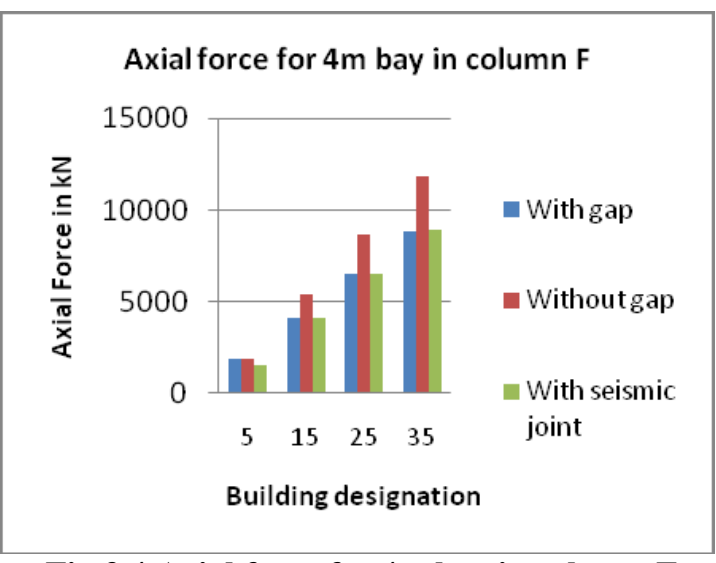

Fig.3.4 Axial force for $4 \mathrm{~m}$ bay in column-F

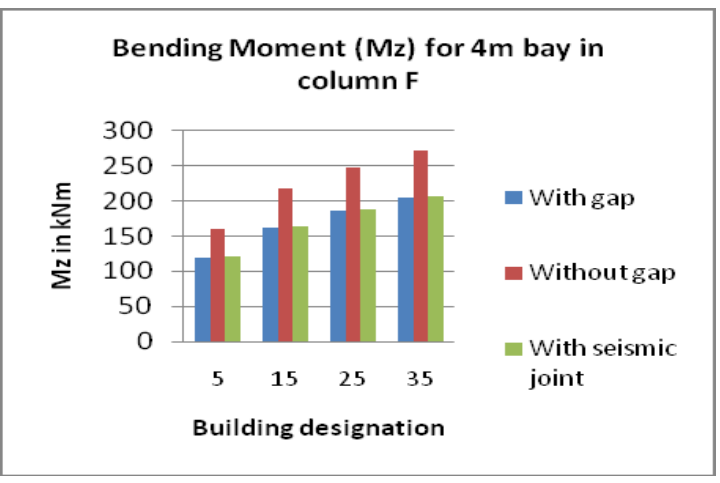

Fig. 3.6 Bending Moment for $\mathbf{4 m}$ bay in column-F

Shear force for $\mathbf{4} \mathrm{m}$ bay in column $\mathrm{F}$

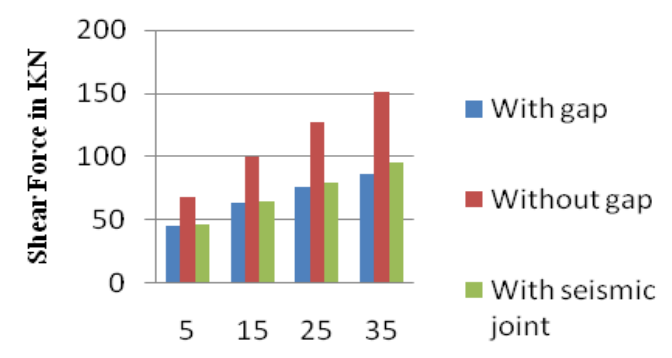

Building designation

Fig.3.8. Shear force for $4 \mathrm{~m}$ bay in column-F

\subsubsection{Graphs without In-filled Wall}

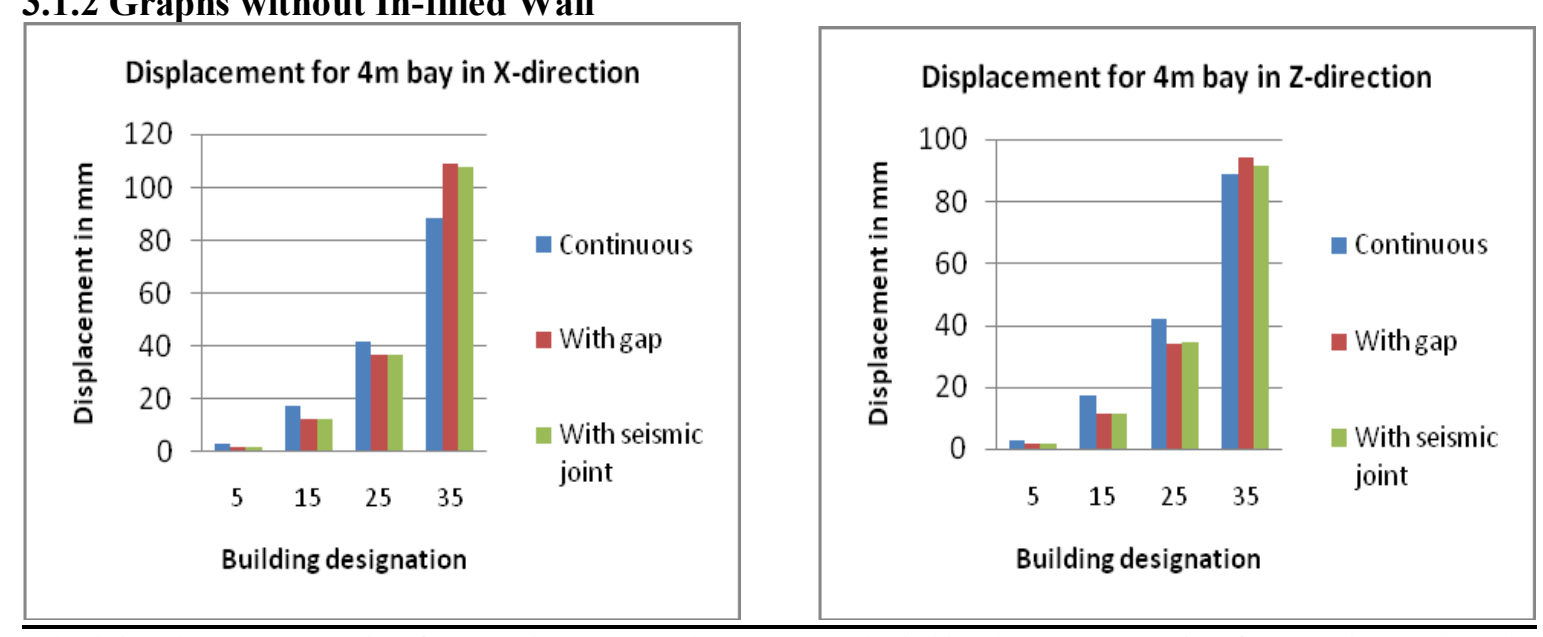

Fig.3.9. Displacement for $\mathbf{4 m}$ bay in X-direction

Fig.3.10.Displacement for $4 \mathrm{~m}$ bay in Z-direction 


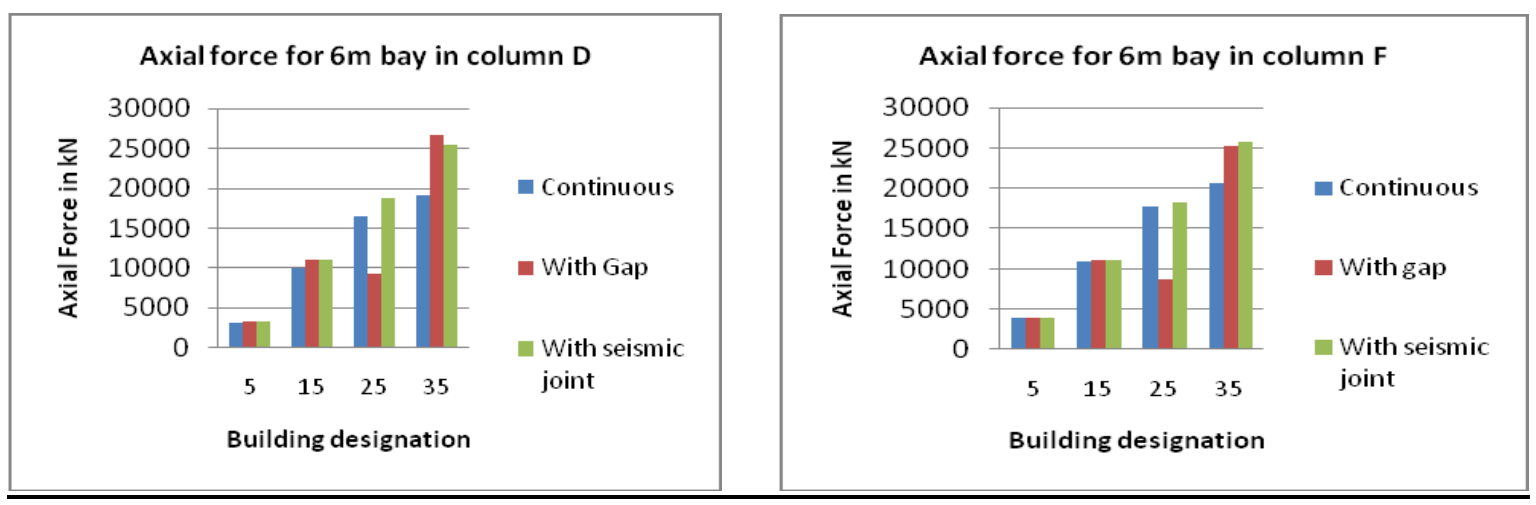

Fig.3.11. Axial force for $4 \mathrm{~m}$ bay in column-D

Fig.3.12 Axial force for $4 \mathrm{~m}$ bay in column-F

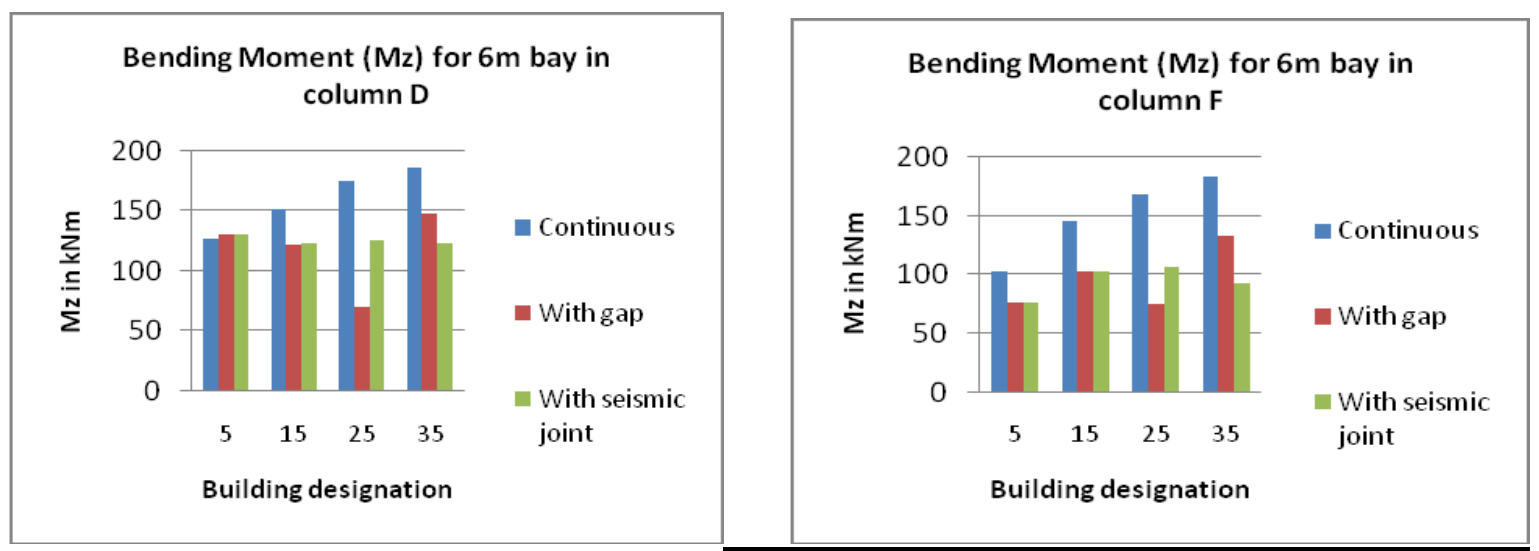

Fig.3.13 Bending Moment for $4 \mathrm{~m}$ bay in column-D

Fig. 3.14 Bending Moment for $4 \mathrm{~m}$ bay in column-F

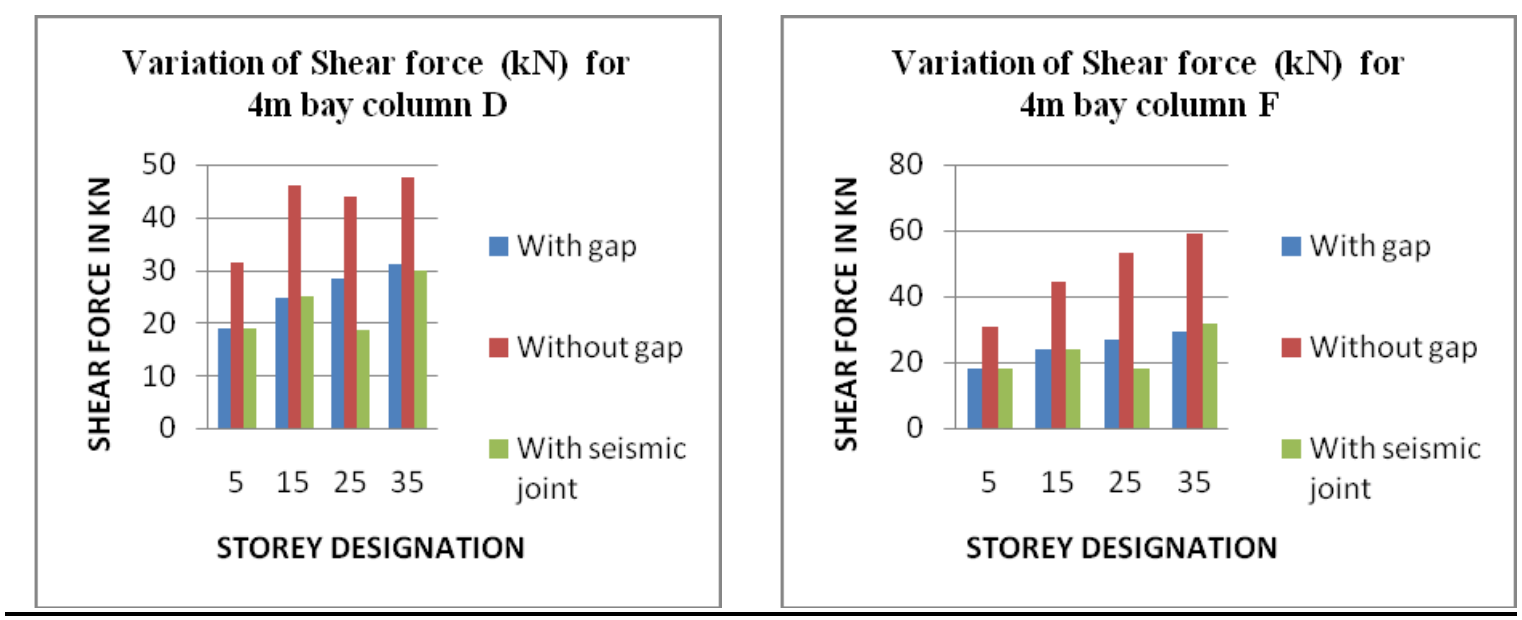

Fig.3.15 Shear force for $4 \mathrm{~m}$ bay in column-D

Fig.3.16 Shear force for $4 \mathrm{~m}$ bay in column-F

\subsection{Discussions}

\subsubsection{Without In-filled Walls:}

1. Column Moments:

a. In without gap condition, the moments increased considerably by 23 to 30 percent in minor-direction and by 15 to 26 percent in major-direction, in comparison with seismic joint and separation gap condition.

b. In $4 \mathrm{~m}$ bay the moments reduced by 30 percent in minor-direction when provided with gap and by 26 percent in major-direction. The moment reduced by 29 to 33 in minor-direction and by 26 to 30 percent when provided with joint in comparison with continuous or without gap condition.

c. In $6 \mathrm{~m}$ bay the moments reduced by 25 percent in minor-direction when provided with gap and by 22 percent in major-direction. The moment reduced by 22 to 25 in minor -direction and by 20 to 24 percent when provided with joint in comparison with continuous or without gap condition. 
d. In $8 \mathrm{~m}$ bay the moments reduced by 22 percent in minor-direction when provided with gap and by 20 percent in major-direction. The moment reduced by 17 to 22 in minor-direction and by 15 to 20 percent when provided with joint in comparison with continuous or without gap condition.

e. It was found that columns F, G, D and C had significant effect of moment compared to other columns. On providing gap or joint the moment reduced more or less equally in two conditions by approximately by 25 percent in $4 \mathrm{~m}$ bay, 20 percent in $6 \mathrm{~m}$ bay, 12 percent in $8 \mathrm{~m}$ bay.

\section{Column Shears:}

a. In without gap condition, shear forces increased considerably by 25 to 30 percent in comparison with seismic joint and separation gap condition.

b. In $4 \mathrm{~m}$ bay the shear forces reduced by 30 percent in minor-direction and by 40 percent in major-direction when provided with gap and reduced by 29 percent in minor-direction and by 37 percent in major-direction when provided with joint in comparison with continuous or without gap condition.

c. In $6 \mathrm{~m}$ bay the shear forces reduced by 25 percent in minor-direction and by 28 percent in major-direction when provided with gap and reduced by 22 percent in minor-direction and by 26 percent in major-direction when provided with joint in comparison with continuous or without gap condition.

d. In $8 \mathrm{~m}$ bay the shear forces reduced by 20 percent in minor-direction and by 24 percent in major-direction when provided with gap and reduced by 20 percent in minor-direction and by 21 percent in major-direction when provided with joint in comparison with continuous or without gap condition.

e. It was found that columns F, G, D and C had significant effect of shear forces compared to other columns. On providing gap the shear force reduced by approximately by 23 percent in $4 \mathrm{~m}$ bay; 20 percent in $6 \mathrm{~m}$ bay; 18 percent in $8 \mathrm{~m}$ bay. On providing seismic joint shear force reduced by approximately by 26 percent in $4 \mathrm{~m}$ bay; 22 percent in $6 \mathrm{~m}$ bay; 20 percent in $8 \mathrm{~m}$ bay.

\section{Axial forces:}

a. In without gap condition, the axial force increased considerably by 23 percent in comparison with seismic joint and separation gap condition.

b. In $4 \mathrm{~m}$ bay the moments reduced by 23 to 30 percent when provided with gap and reduced by 25 to 33 percent when provided with joint in comparison with continuous or without gap condition.

c. In $6 \mathrm{~m}$ bay the moments reduced by 18 to 23 percent when provided with gap and reduced by 19 to 23 percent when provided with joint in comparison with continuous or without gap condition.

d. In $8 \mathrm{~m}$ bay the moments reduced by 11 to 16 percent when provided with gap and reduced by 12 to 18 percent when provided with joint in comparison with continuous or without gap condition.

e. It was found that columns $\mathrm{F}, \mathrm{G}$ and $\mathrm{C}$ had significant effect of axial and shear forces compared to other columns. On providing gap the shear force reduced by approximately by 26 percent in $4 \mathrm{~m}$ bay; 22 percent in $6 \mathrm{~m}$ bay; 16 percent in $8 \mathrm{~m}$ bay. On providing seismic joint shear force reduced by approximately by 30 percent in $4 \mathrm{~m}$ bay; 23 percent in $6 \mathrm{~m}$ bay; 18 percent in $8 \mathrm{~m}$ bay.

\subsubsection{With brick in-filled walls:}

1. Column Moments:

a. In without gap condition, the moments increased considerably by 25 percent in minor-direction and by 27 percent in major-direction, in comparison with seismic joint and separation gap condition.

b. In $4 \mathrm{~m}$ bay the moments reduced by 52 percent in minor-direction when provided with gap and by 45 percent in major-direction. The moment reduced by 64 in minor-direction and by 59 percent when provided with joint in comparison with continuous or without gap condition.

c. In $6 \mathrm{~m}$ bay the moments reduced by 65 percent in minor-direction when provided with gap and by 61 percent in major-direction. The moment reduced by 58 in minor-direction and by 54 percent in majordirection when provided with joint in comparison with continuous or without gap condition.

d. In $8 \mathrm{~m}$ bay the moments reduced by 46 percent in minor-direction when provided with gap and by 48 percent in major-direction. The moment reduced by 50 in minor-direction and by 40 percent in majordirection when provided with joint in comparison with continuous or without gap condition.

e. It was found that columns F, G, D and C had significant effect of moment compared to other columns. On providing joint the moment reduced more by approximately by 65 percent in $4 \mathrm{~m}$ bay; 58 percent in $6 \mathrm{~m}$ bay; 50 percent in $8 \mathrm{~m}$ bay. On providing gap shear force reduced by approximately by 52 percent in $4 \mathrm{~m}$ bay; 60 percent in $6 \mathrm{~m}$ bay; 46 percent in $8 \mathrm{~m}$ bay. 


\section{Column shears}

a. In without gap condition, shear forces increased considerably by 30 percent in comparison with seismic joint and separation gap condition.

b. In $4 \mathrm{~m}$ bay the shear forces reduced by 64 percent in minor-direction and by 67 percent in major-direction when provided with gap and reduced by 75 percent in minor -direction and by 76 percent in major direction when provided with joint in comparison with continuous or without gap condition.

c. In $6 \mathrm{~m}$ bay the shear forces reduced by 78 percent in minor -direction and by 77 percent in major -direction when provided with gap and reduced by 61 percent in minor -direction and by 64 percent in major direction when provided with joint in comparison with continuous or without gap condition.

d. In $8 \mathrm{~m}$ bay the shear forces reduced by 50 percent in minor -direction and by 48 percent in major -direction when provided with gap and reduced by 46 percent in minor - direction and by 49 percent in major direction when provided with joint in comparison with continuous or without gap condition.

e. It was found that columns F, G, D and C had significant effect of shear forces compared to other columns. On providing gap or joint the shear force reduced by more or less equally by approximately 70 percent in $4 \mathrm{~m}$ bay; 60 percent in $6 \mathrm{~m}$ bay; 50 percent in $8 \mathrm{~m}$ bay.

\section{Axial forces:}

a. In without gap condition, the axial force increased considerably by 25 percent in comparison with seismic joint and separation gap condition.

b. In $4 \mathrm{~m}$ bay the moments reduced by 51 percent when provided with gap and reduced by 75 percent when provided with joint in comparison with continuous or without gap condition.

c. In $6 \mathrm{~m}$ bay the moments reduced by 50 percent when provided with gap and reduced by 30 percent when provided with joint in comparison with continuous or without gap condition.

d. In $8 \mathrm{~m}$ bay the moments reduced by 15 percent when provided with gap and reduced by 12 percent when provided with joint in comparison with continuous or without gap condition.

e. It was found that columns F, G, D and C had significant effect of axial forces compared to other columns. On providing gap the axial force reduced by approximately by 51 percent in $4 \mathrm{~m}$ bay; 49 percent in $6 \mathrm{~m}$ bay; 14 percent in $8 \mathrm{~m}$ bay. On providing seismic joint shear force reduced by approximately by 70 percent in $4 \mathrm{~m}$ bay; 25 percent in $6 \mathrm{~m}$ bay; 11 percent in $8 \mathrm{~m}$ bay.

Results indicate a general trend in the columns chosen for observation in all the three parameters considered for study namely viz. moment, shear and axial force in columns. The absolute minimum value of all the three parameters are observed to be increasing with storey height and bay width of the building as well, for continuity conditions at the junctions and decreasing for gap and seismic joint condition at the junction. Understandably the continuity effect is contributing for the increment in the chosen parameter, while the gap or seismic joint conditions are imparting discontinuity to the structure at the junction. The result hints towards providing a seismic joint in a gap in such L-shaped building for better seismic performance.

\section{Conclusions:}

It is observed that proving brick infill has shown considerable and acceptable effects compare to without brick infill.

1. By providing brick infill, the moments have reduced by more 20 percent in comparison to those without infill materials.

2. Shear forces have reduced by approximately 30 percent in excess in models with brick infill compared to without infill case.

3. Comparing the two cases, brick in-filled models proved effective by reducing the axial forces by approximately 30 percent more in comparison to without infill case.

4. Seismic joint proved effective in $4 \mathrm{~m}$ bay whether provided with brick infill or without infill. The effect of joint was more or less equal or less compared to seismic gap in $6 \mathrm{~m}$ and $8 \mathrm{~m}$ bay conditions.

\section{REFERENCES}

[1] Ujjwal Sur,Shri B.S. Sokhi, Vulnerability Assessment of Building and Population Related to Earthquake Hazard in Dehra Dun City using Remote Sensing and Geoinformation Techniques, HUSAD, IIRS.

[2] T. Slak and V. Kilar, Initial conceptual design of earthquake resistant $\mathrm{r} / \mathrm{c}$ and masonry buildings according to Eurocode 8, University of Ljubljana, Faculty of Architecture, Slovenia

[3] Dr. S.K. Dubey, P.D. Sangamnerkar, Seismic Behavior of Asymmetric RC Buildings, International Journal of Advanced Engineering Technology, E-ISSN 0976-3945.

[4] Shunsuke Otani, Earthquake Resistant Design of Reinforced Concrete Buildings, International Conference on Concrete and Development at Tehran.

[5] William E. Gates, Torsional control of two adjacent office buildings using viscous dampers, ATC-17-2 
[6] Osamu Yoshida and Shirley J. Dyke, Response Control in Full Scale Irregular Buildings Using MR Dampers, ASCE Journal of Structural Engineering, June 2003.

[7] Ferhi, A., and Truman, K. Z. (1996). Behavior of asymmetric building systems under a monotonic load - I, Engineering Structures, Vol. 18, No. 2, pp. 133-141.

[8] Kan, C. L., and Chopra, A. K. (1977). Effect of Torsional Coupling on Earthquake Force in Buildings, Journal of the Structural Division, ASCE, 103, pp. 805-820

[9] Lopez, Oscar A. Raven, Elizabeth, Overall Evaluation of Irregular-Floor-Plan-Shaped Buildings Located In Seismic Areas, Earthquake Spectra, Volume 15, number 1, February 1999, pages 105-120

[10] C. Rajaram and Pradeep K. R. ,Comparision of Codal Provisions on Pounding Between Adjacent Buildings, International Journal of Earth Sciences and Engineering, February 2012, P.P. 72-82

[11] IS 1893 (Part - I):2002, "Criteria For Earthquake Resistant Design Of Structures", (Bureau of Indian Standards), New Delhi, India. 